\title{
Role of Cav2.1 Channel Signaling in Glutamate-Related Brain Injury
}

Tae Yeon Kim*, Kimie Niimi, and Eiki Takahashi

Research Resources Center, RIKEN Brain Science Institute, 2-1 Hirosawa, Wako, Saitama, Japan

\begin{abstract}
Voltage-gated $\mathrm{Ca}^{2+}$ channels (VGCCs) play a pivotal role in intracellular processes such as neurotransmitter release, axonal outgrowth, membrane excitability, and synaptic plasticity. Three major presynaptic Cav2 channels, including the Cav2.1 channel, are involved in the mechanism underlying $\mathrm{Ca}^{2+}$-dependent excitotoxicity. Glutamate is among the excitatory neurotransmitters regulated by the Cav2.1 channel. Glutamate-related excitotoxicity is a pathological process associated with seizures, traumatic brain injury, and cerebral ischemia. This review emphasizes the relationship between activation of the Cav2.1 channel and these various types of brain injury.
\end{abstract}

Keywords: Cav2.1; Glutamate; Excitotoxicity; Brain injury

\section{Types of Brain Injury}

Cerebral ischemia, seizures, traumaticbrain injury. Neuroprotection has been studied worldwide in the context of brain injuries, including neurodegenerative diseases, cerebral ischemia, epilepsy and seizures, and traumatic brain injury (TBI) [1-3]. Cerebral ischemia is one of the most common causes of death in adults worldwide, resulting in necrosis and apoptosis in the brain that in turn leads to a high possibility of ischemic stroke-related disability [4-6]. Epilepsy, characterized by multiple, unpredictable seizures, is a common neuronal disease in human populations regardless of age, sex, or race. Approximately $1 \%$ of the population worldwide is known to have epilepsy, which often requires lifelong medication [7]. TBI, which is typically due to falls or motor vehicle- or sports-related accidents, is a serious health issue regardless of age [8]. Approximately 1.4 million patients visit emergency rooms in the USA each year due to TBI [9]. The need for treatment of such brain injuries appears to be dramatically increasing. Therefore, in this paper, we review the role of the Cav2.1 channel in cerebral ischemia, seizures, and TBI.

\section{Voltage-Gated $\mathrm{Ca}^{2+}$ Channels}

\section{Structure, subtypes, and function}

Voltage-gated $\mathrm{Ca}^{2+}$ channels (VGCCs) are located in presynapses in the central nervous system (CNS) [10-12]. $\mathrm{Ca}^{2+}$ influx via VGCCs regulates intracellular processes such as neurotransmitter release, axonal outgrowth, membrane excitability, and synaptic plasticity [10]. Glutamate signaling is among the types of signaling regulated by the Cav2.1 channel $[13,14]$. VGCCs are molecular complexes composed of four subunits that are encoded by multiple, distinct genes: $\alpha_{1}, \alpha_{2} / \delta, \beta$, and $\gamma[10,11,15]$ (Figure 1). The $\alpha_{1}$ subunit, which is the largest pore-forming subunit, consists of four homologous transmembrane domains (I-IV), each of which contains six membrane-spanning helices (S1-S6) and a reentrant p-loop. Cytoplasmic linkers connect the four domains. Both the cytoplasmic $\mathrm{C}$ - and $\mathrm{N}$-termini interact with regulatory proteins [16] and play an essential role in VGCC functions and properties, such as voltage sensing and protein binding $[11,15,16]$. VGCCs are functionally divided into several subtypes: the Cav1 (L-type), Cav2.1 (P/Q-type), Cav2.2 (N-type), Cav2.3 (R-type), and Cav3 (T-type) channels. Cav1, Cav2.1, Cav2.2, and Cav2.3 are high voltage-gated channels, whereas Cav3 is a low voltage-gated channel. Each channel has different functions and pharmacological characteristics. The Cav1 channel, which is inhibited by dihydropyridines, phenylalkylamines, and benzothiazepines, is involved in excitation-contraction coupling, $\mathrm{Ca}^{2+}$

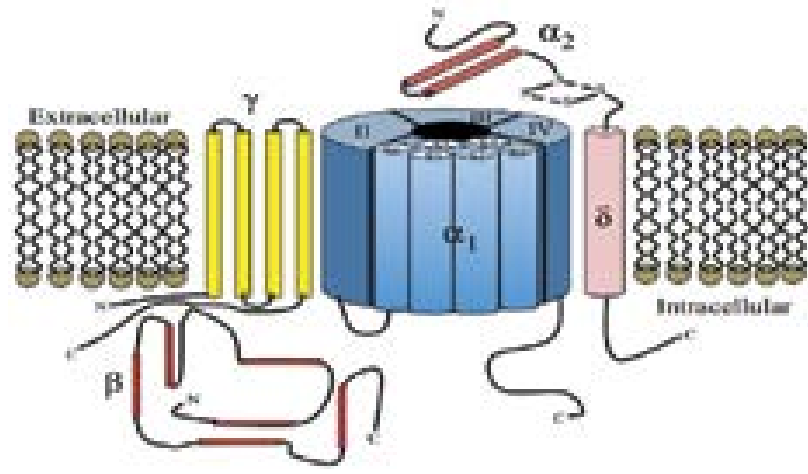

Figure 1: Structure of high voltage-gated $\mathrm{Ca}^{2+}$ channels (VGCCs). High VGCCs are molecular complexes consisting of $\alpha_{1}, \alpha_{2} / \delta, \beta$, and $y$ subunits. The $\alpha_{1}$ subunit comprises four homologous transmembrane domains (I-IV), each containing six membrane-spanning helices (S1-S6) and a reentrant p-loop motif that lines the channel pore. The four domains are connected through cytoplasmic linkers, and both the $\mathrm{C}$ - and $\mathrm{N}$-termini are cytoplasmic.

homeostasis, gene regulation, and neurotransmitter release. $\omega$-agatoxin IVA ( $\omega$-aga) is a Cav2.1 channel antagonist and $\omega$-conotoxin GVIA is a Cav2.2 channel antagonist. Both the Cav2.1 and Cav2.2 channels are important for neurotransmitter and hormone release, as well as for generating dendritic $\mathrm{Ca}^{2+}$ transients. The Cav2.3 channel, which is inhibited by SNX-482, is associated with repetitive firing and the generation of dendritic $\mathrm{Ca}^{2+}$ transients. The Cav3 channel, for which no selective antagonist has yet been identified, is involved in pacemaking and repetitive firing $[16,17]$. Among the various VGCCs, the Cav2.1 and Cav2.2 channels are the most involved in neurotransmitter release in the CNS, and are also associated with the mechanism underlying $\mathrm{Ca}^{2+}$-dependent excitotoxicity. Each VGCC has antagonists, such as $\omega$-aga for the Cav2.1 channel (Table 1).

*Corresponding author: Tae Yeon Kim, DVM. Research Resources Center RIKEN Brain Science Institute 2-1 Hirosawa, Wako, Saitama, 351-0198, Japan, Tel: +81484675871; Fax: +81-48-467-9692; E-mail: taeyeonkim@brain.riken.jp

Received October 03, 2016; Accepted November 23, 2016; Published November 29, 2016

Citation: Kim TY, Niimi K, Takahashi E (2016) Role of Cav2.1 Channel Signaling in Glutamate-Related Brain Injury. Brain Disord Ther 5: 226. doi: 10.4172/2168975X.1000226

Copyright: (C) $2016 \mathrm{Kim}$ TY, et al. This is an open-access article distributed under the terms of the Creative Commons Attribution License, which permits unrestricted use, distribution, and reproduction in any medium, provided the original author and source are credited. 
Citation: Kim TY, Niimi K, Takahashi E (2016) Role of Cav2.1 Channel Signaling in Glutamate-Related Brain Injury. Brain Disord Ther 5: 226. doi: 10.4172/2168-975X.1000226

\section{Mutations in the Cav2.1 $\alpha_{1}$ subunit}

The $\alpha_{1}$ subunit of the Cav2.1 channel (Cav2.1 $\left.\alpha_{1}\right)$ is encoded in the CACNA1A gene in humans. Mutations in the Cav2.1 $\alpha$ gene induce autosomal-dominant symptoms and disorders, including familiar hemiplegic migraine type 1 (FHM1), episodic ataxia type 2 (EA2), spinocerebellar ataxia type 6 (SCA6), and epilepsy $[10,15]$. Mutations in the Cav2.1 $\alpha$, gene have been observed in mice (Figure 2). Several types of spontaneous mutant mice with mutations in the cacnala gene on chromosome 8 have been reported, including rocker (rkr), tottering (tg), rolling Nagoya, wobbly, tottering- $4 \mathrm{j}$, tottering-5j, tottering- $6 \mathrm{j}$, and leaner (la) mice. Among these mutations, tottering-5j and wobbly

\begin{tabular}{|c|c|c|}
\hline Cav subtype & Antagonist & Physiological function \\
\hline Cav1 (L-type) & $\begin{array}{l}\text { Dihydropyridine } \\
\text { Phenylalkylamines } \\
\text { Benzothiazepines }\end{array}$ & $\begin{array}{l}\text { Excitation-contraction coupling } \\
\text { Calcium homeostasis } \\
\text { Gene regulation Neurotransmitter } \\
\text { release }\end{array}$ \\
\hline Cav2.1 (P/Q-type) & $\omega$-agatoxin IVA & $\begin{array}{c}\text { Neurotransmitter release, } \\
\text { dendritic } \mathrm{Ca}^{2+} \text { transient currents }\end{array}$ \\
\hline Cav2.2 (N-type) & $\omega$-conotoxin GVIA & $\begin{array}{l}\text { Neurotransmitter release } \\
\text { Dendritic } \mathrm{Ca}^{2+} \text { transients } \\
\text { Hormone release }\end{array}$ \\
\hline Cav2.3 (R-type) & SNX-482 & $\begin{array}{c}\text { Repetitive firing } \\
\text { Dendritic } \mathrm{Ca}^{2+} \text { transients }\end{array}$ \\
\hline Cav3 (T-type) & No selective antagonist & $\begin{array}{l}\text { Pacemaking } \\
\text { Repetitive firing }\end{array}$ \\
\hline
\end{tabular}

Table 1: Physiological function and pharmacology of Cav channel subtypes.

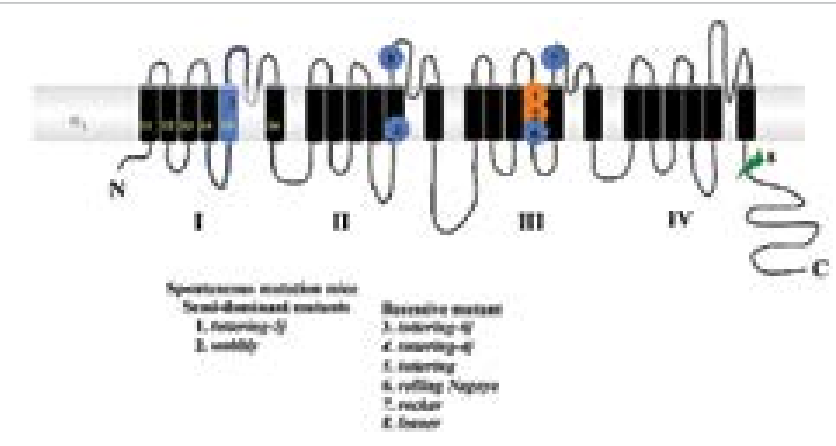

Figure 2: Location of mouse mutations in the secondary Cav2.1 $\alpha_{1}$ structure The tottering-5j and wobbly mutations are semi-dominant, whereas the tottering, rolling Nagoya, rocker, leaner, tottering- $4 \mathrm{j}$, and tottering-6j mutations are recessive.

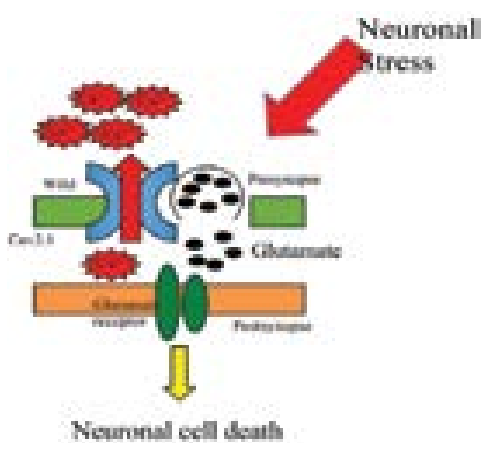

Figure 3: Putative mechanism for mutant Cav2.1 channel-related p38 mitogenactivated protein kinases (MAPK) signaling. VGCCs play an important role in glutamate signaling. Abnormal $\mathrm{Ca}^{2+}$ influx leads to p38 MAPK signaling disturbance. are semi-dominant and the others are recessive [10]. The mutant mice show symptoms similar to those of humans.

\section{Glutamate}

Glutamate, the major endogenous excitatory neurotransmitter, is coupled to the glutamatergic system in the CNS [14]. Glutamate binds to post-synaptic glutamate receptors, including ionotropic glutamate, kainate, a-amino-3-hydroxy-5-methyl-4-isoxazolepropionic acid (AMPA), and N-methyl-D-aspartate (NMDA) receptors [18]. Glutamate-induced excitotoxicity is considered an important mechanism underlying neuronal death in ischemia, CNS trauma, and epilepsy [19]. Neuronal stress leads to excessive release of glutamate, which over activates post-synaptic glutamate receptors and causes neurodegeneration [20]. Many studies have reported that NMDA is involved in excitotoxicity [21-23], while AMPA is involved in neuronal cell death related to oxygen/glucose deprivation [24], ischemia [25], seizures [26], and TBI [27]. Kainate, a well-known cause of epilepsy, induces persistent high-amplitude, high-frequency spikes [28].

\section{Studies on the protective role of the Cav2.1 channel against brain injury}

\section{Seizure}

The Cav2.1 channel is among the VGCCs most involved in synaptic transmission. Abnormalities in the Cav2.1 channel affect cellular and neuronal networks, leading to seizure [29-30]. The Cav2.1 channel is involved in glutamate signaling $[13,14]$.

Kainate injection has been used in experimental models of seizures [31-33]. Kainate binds to both kainate and AMPA receptors [31,32]. Following kainate-induced seizures, neuronal loss in the hippocampus is observed, along with the appearance of reactive astrocytes and delayed neuronal cell death [34]. A study using Cav2.1 channel mutant mice reported that seizures and neuronal damage were reduced in animals injected with kainate compared to wild-type controls, suggesting that the kainate/AMPA signaling gateway may be suppressed by Cav2.1 channel dysfunction, leading to resistance against excitotoxicity [26]. In the same study, the expression of pp38 was not increased in kainate-injected Cav2.1 mutant mice relative to kainate-injected $+/+$ mice. These results suggest that changes in the threshold for glutamate release, via depolarization-induced $\mathrm{Ca}^{2+}$ influx through the mutant Cav2.1 channel, induce abnormal glutamate receptor function and postsynaptic p38 mitogen-activated protein kinases (MAPK) signaling cascades (Figure 3). The seizure scores of kainate-injected heterozygous p38 knockout mouse are significantly lower than those of $+/+$ mice [34]. Kim et al. [35] reported that inhibition of p38 MAPK significantly attenuates both neuronal loss in the hippocampus and the accompanying gliosis. This accords with studies that have shown that the p38 MAPK pathway is involved in seizures and apoptotic processes $[34,36]$.

Antiepileptic drugs, such as Lamotrigine and Levetiracetam, Cav2.1 channel blockers, have been used for treating seizure successfully [37]. However, these drugs don't solely block Cav2.1 channels. Lamotrigine, Cav3 channel, Cav2.1-2.3, sodium channel, A-type potassium channel inhibitor, is a broad-spectrum antiepileptic drug [37]. It is used for monotherapy and also for adjunctive therapy. Levetiracetam inhibits high VGCCs such as, Cav2.1 and Cav2.2. It also inhibits potassium current and reduces GABA turnover rate [37]. Clinical trials regarding Cav2.1 channel selective inhibition have not been widely conducted. Further studies focusing on Cav2.1 inhibition is warranted. 


\section{Traumatic brain injury}

TBI induces both primary and secondary brain damage. Primary (mechanical) damage, for example from a cryogenic stimulus, can damage the brain cortex, whereas secondary damage involves astrocytes and neurons. Abnormal release of neurotransmitters, including glutamate, induces excitotoxicity; TBI is associated with glutamate signaling [38-40].

In a study that induced brain injury using a cryogenic method, Cav2.1 channel mutant mice had smaller lesions compared to $+/+$ mice; the degree of neuronal damage and number of reactive astrocytes were also lower the Cav2.1 channel mutants [41]. These results indicate that mutations in the Cav2.1 channel can protect against the excitotoxicity induced by cryogenic brain injury and decreased $\mathrm{Ca}^{2+}$ influx by attenuating astrocyte reactivation [41]. In addition, in that same study, administration of $\omega$-aga into the lateral ventricle $24 \mathrm{~h}$ after cryogenic injury had a therapeutic effect, shown by smaller lesions as well as fewer degenerated cells and reactive astrocytes [41]. Further study on the behavioral effects of $\omega$-aga treatment is warranted. That same study also showed that neuronal cells in vehicle-treated mice showed greater levels of pp38 expression compared to mice treated with $\omega$-aga. Similar to kainate-induced seizures, these results indicate that the Cav2.1 channel is involved in the p38 MAPK signaling cascade (Figure 3).

In clinical trial, administrating Cav1 channel antagonist improved outcome when injected acutely [42]. Clinical trial regarding Ziconotide, Cav2.2 channel blocker, was conducted, however due to the side effect the study was halted [42]. Future studies are needed for Cav2.1 channel antagonist.

\section{Cerebral ischemia}

Cerebral ischemia is defined as a level of blood flow to the brain that is insufficient to maintain normal cellular function [43]; this blood flow restriction leads to a massive release of glutamate. Overactivation of NMDA and AMPA receptors results in neuronal death and dysfunction $[43,44]$. Induced middle cerebral artery occlusion has been used in numerous cerebral ischemia models [45-48]. In such models, the caudate putamen and cerebral cortex become the ischemic core and penumbra area, respectively $[43,44]$.

Excessive intracellular $\mathrm{Ca}^{2+}$ influx plays an important role in neuronal cell death following cerebral ischemia [49]. For example, Cav2.1 channel mutant mice show a smaller infarct area than wild-type mice [45]. As mentioned previously, glutamate signaling is regulated by the Cav2.1 channel $[13,14]$. This suggests that the protective effects of Cav2.1 channel mutations against cerebral ischemia might be due to a disturbance in glutamate signaling. Many studies have suggested that the p38 MAPK pathway plays a central role in cerebral ischemia by facilitating inflammatory responses. In one such study, changes in the glutamate excretion threshold, via mutation of the Cav2.1 channel, induced abnormal glutamate receptor function and postsynaptic p38 MAPK signaling cascades (Figure 3) [50].

Using Cav2.1 channel antagonist for treatment has not been studies in clinical level. However, a study conducted on rats demonstrated that injecting Cav2.1 blocker has protective effect against ischemia [48]. Further studies are warranted.

\section{Conclusion}

VGCCs play important roles in neurotransmitter release, neuronal survival, and calcium-dependent gene transcription. Three major presynaptic Cav2 channels, namely the Cav2.1, Cav2.2, and Cav2.3 channels, are involved in the mechanism underlying $\mathrm{Ca}^{2+}$-dependent excitotoxicity [10]. While the therapeutic value of the Cav2.2 and Cav2.3 channels has been reported, little is known about the potential of the Cav2.1 channel as a target for therapeutics.

Mutations in the Cav2.1 channel had a protective effect against kainate-induced seizures, TBI, and cerebral ischemia, suggesting that the Cav2.1 channel is coupled to kainate/AMPA receptor signaling. Cav2.1 channel mutations also conferred protection against TBI and cerebral ischemia, while $\omega$-aga treatment was effective for TBI recovery [41].

Taken together, these data suggest that Cav2.1 channel inhibitors are likely to hold the key to successful brain injury therapies in the future.

\section{References}

1. Lalkovicova M, Danielisova V (2016) Neuroprotection and antioxidants. Neural Regen Res 11: 865-874.

2. Shasha Liu, Weihua Yu, Yang Lü (2016) The causes of new-onset epilepsy and seizures in the elderly. Neuropsychiatr Dis Treat 12: 1425-1434.

3. Nagae LM, Lall N, Dahmoush H, Nyberg E, Mirsky D, et al. (2016) Diagnostic, treatment, and surgical imaging in epilepsy. Clin Imaging 40: 624-636.

4. Lee SH, Kim M, Yoon BW, Kim YJ, Ma SJ, et al. (2001) Targeted hsp70.1 disruption increases infarction volume after focal cerebral ischemia in mice. Stroke 32: 2905-2912.

5. Carter AM, Catto AJ, Mansfield MW, Bamford JM, Grant PJ (2007) Predictive variables for mortality after acute ischemic stroke. Stroke 38: 1873-1880.

6. Donnan GA, Fisher M, Macleod M, Davis SM (2008) Stroke. Lancet 371: 1612-1623.

7. Hauser WA, Annegers JF, Kurland LT (1993) Incidence of epilepsy and unprovoked seizures in Rochester, Minnesota: 1935-1984. Epilepsia 34: 453-468.

8. https://www.cdc.gov/traumaticbraininjury/pdf/blue_book.pdf

9. Lozano D, Gonzales-Portillo GS, Acosta S, de la Pena I, Tajiri N, et al. (2015) Neuroinflammatory responses to traumatic brain injury: Etiology, clinical consequences, and therapeutic opportunities. Neuropsychiatr Dis Treat 11 97-106.

10. Takahashi E (2012) Cav2.1 channelopathies and mouse genetic approaches to investigate function and dysfunction of Cav2.1 channel. In: Yamaguchi M (Ed). Calcium signaling. New York: Nova Science Publishers, Inc.

11. Simms BA, Zamponi GW (2014) Neuronal voltage-gated calcium channels: Structure, function, and dysfunction. Neuron 82: 24-45.

12. Heyes S, Pratt WS, Rees E, Dahimene S, Ferron L, et al. (2015) Genetic disruption of voltage-gated calcium channels in psychiatric and neurological disorders. Prog Neurobiol 134: 36-54.

13. Turner TJ, Adams ME, Dunlap K (1992) Calcium channels coupled to glutamate release identified by omega-Aga-IVA. Science 258: 310-313.

14. Lee CY, Chen CC, Liou HH (2009) Levetiracetam inhibits glutamate transmission through presynaptic P/Q-type calcium channels on the granule cells of the dentate gyrus. Br J Pharmacol. 158: 1753-1762.

15. Zamponi GW, Striessnig J, Koschak A, Dolphin AC (2015) The physiology, pathology, and pharmacology of voltage-gated Calcium channels and their future therapeutic potential. Pharmacol Rev 67: 821-870.

16. Takahashi E, Niimi K (2009) Modulators of voltage-dependent calcium channels for the treatment of nervous system diseases. Recent Pat CNS Drug Discov 4 96-111.

17. Catterall WA, Perez-Reyes E, Snutch TP, Striessnig J (2005) International union of pharmacology. XLVIII. Nomenclature and structure-function relationships of voltage-gated calcium channels. Pharmaco Rev 57: 411-425.

18. Rojas A, Dingledine R (2013) lonotropic glutamate receptors: Regulation by G-protein-coupled receptors. Mol Pharmacol 83: 746-752.

19. Rajendra W, Armugam A, Jeyaseelan K (2004) Neuroprotection and peptide toxins. Brain Res Brain Res Rev 45: 125-141. 
Citation: Kim TY, Niimi K, Takahashi E (2016) Role of Cav2.1 Channel Signaling in Glutamate-Related Brain Injury. Brain Disord Ther 5: 226. doi: 10.4172/2168-975X.1000226

20. Mokrushin AA (2016) Mystixin-7 peptide protects ionotropic glutamatergic mechanisms against glutamate-induced excitotoxicity in vitro. Int J Pept 2016: 5151843.

21. Molz S, Decker H, Dal-Cim T, Cremonez C, Cordova FM, et al. (2008) Glutamate-induced toxicity in hippocampal slices involves apoptotic features and p38 MAPK signaling. Neurochem Res 33: 27-36.

22. Lai TW, Zhang S, Wang YT (2014) Excitotoxicity and stroke: Identifying novel targets for neuroprotection. Prog Neurobiol 115: 157-188.

23. Parsons MP, Raymond LA (2014) Extrasynaptic NMDA receptor involvement in central nervous system disorders. Neuron 82: 279-293.

24. Park YH, Broyles HV, He S, McGrady NR, Li L, et al. (2016) Involvement of AMPA receptor and its flip and flop isoforms in retinal ganglion cell death following oxygen/glucose deprivation. Invest Ophthalmol Vis Sci 57: 508-526.

25. Tang Z, Li S, Han P, Yin J, Gan Y, et al. (2015) Pertussis toxin reduces calcium influx to protect ischemic stroke in a middle cerebral artery occlusion model. $J$ Neurochem 135: 998-1006.

26. Kim TY, Yoshimoto T, Aoyama Y, Niimi K, Takahashi E, et al. (2014) Agedependent kainate sensitivity in heterozygous rolling Nagoya Cav2.1 channel mutant mice. Pharmacol Biochem Behav 124: 250-259

27. Chen T, Dai SH, Jiang ZQ, Luo P, Jiang XF, et al. (2016) The ampar antagonist perampanel attenuates traumatic brain injury through anti-oxidative and antiinflammatory activity. Cell Mol Neurobiol .

28. Williams P, White A, Ferraro D, Clark S, Staley K, et al. (2006) The use of radiotelemetry to evaluate electrographic seizures in rats with kainate-induced epilepsy. J Neurosci Methods 155: 39-48.

29. Evans RM, Zamponi GW (2006) Presynaptic $\mathrm{Ca}^{2+}$ channels-integration centers for neuronal signaling pathways. Trends Neurosci 29: 617-624.

30. Jarvis SE, Zamponi GW (2007) Trafficking and regulation of neuronal voltagegated calcium channels. Curr Opin Cell Biol 19: 474-482.

31. Contractor A, Mulle C, Swanson GT (2011) Kainate receptors coming of age: milestones of two decades of research. Trends Neurosci 34: 154-163.

32. Bassani S, Folci A, Zapata J, Passafaro M (2013) AMPAR trafficking in synapse maturation and plasticity. Cell Mol Life Sci 70: 4411-4430.

33. Faught E (2014) BGG492 (selurampanel), an AMPA/kainate receptor antagonis drug for epilepsy. Expert Opin Investig Drugs 23: 107-113.

34. Namiki K, Nakamura A, Furuya M, Mizuhashi S, Matsuo Y, et al. (2007) Involvement of p38alpha in kainate-induced seizure and neuronal cell damage. J Recept Signal Transduct Res. 27: 99-111.

35. Kim SW, Yu YM, Piao CS, Kim JB, Lee JK (2004) Inhibition of delayed induction of p38 mitogen-activated protein kinase attenuates kainic acid-induced neuronal loss in the hippocampus. Brain Res 1007: 188-191.

36. Herlaar E, Brown Z (1999) p38 MAPK signaling cascades in inflammatory disease. Mol Med Today 5: 439-447.
37. Weiergraber M, Stephani U, Köhling R (2010) Voltage-gated calcium channels in the etiopathogenesis and treatment of absence epilepsy. Brain Res Rev. 62 245-271.

38. Rachmany L, Tweedie D, Rubovitch V, Yu QS, Li Y, et al. (2013) Cognitive impairments accompanying rodent mild traumatic brain injury involve p53-dependent neuronal cell death and are ameliorated by the tetrahydrobenzothiazole PFT- $\alpha$. PLoS One 8: e79837.

39. Shohami E, Biegon A (2014) Novel approach to the role of NMDA receptors in traumatic brain injury. CNS Neurol Disord Drug Targets 13: 567-573.

40. Gao Y, Xu S, Cui Z, Zhang M, Lin Y, et al. (2015) Mice lacking glutamate carboxypeptidase II develop normally, but are less susceptible to traumatic brain injury. J Neurochem 134: 340-353.

41. Kim TY, Yoshimoto T, Aoyama Y, Niimi K, Takahashi E (2016) Analysis of the protective effects of a neuronal Cav2.1 calcium channel in brain injury. Neuroscience 313: 110-121.

42. Gurkoff G, Shahlaie K, Lyeth B, Berman R (2013) Voltage-Gated Calcium Channel Antagonists and Traumatic Brain Injury. Pharmaceuticals (Basel). 6 : 788-812.

43. Uchino H, Ogihara Y, Fukui H, Chijiiwa M, Sekine S, et al. (2016) Brain injury following cardiac arrest: pathophysiology for neurocritical care. J Intensive Care 4: 31.

44. Castillo J, Loza MI, Mirelman D, Brea J, Blanco, M, et al. (2016) A nove mechanism of neuroprotection: Blood glutamate grabber. J Cereb Blood Flow Metab 36: 292-301.

45. Tian X, Zhou Y, Gao L, He G, Jiang W, et al. (2013) Analysis of ischemic neuronal injury in Cav2.1 channel a1 subunit mutant mice. Biochem Biophys Res Commun 434: 60-64.

46. Altintas O, Altintas MO, Aydin MS, Baran O, Antar V, et al. (2016) Neuroprotective effects of chronic fenofibrate treatment via modulating the immunoreactivity of cleaved caspase-3 in stroke induced by transient middle cerebral occlusion rat model. Turk Neurosurg Feb 5.

47. El Amki M, Clavier T, Perzo N, Bernard R, Guichet PO, et al. (2015) Hypothalamic, thalamic and hippocampal lesions in the mouse MCAO model: Potential involvement of deep cerebral arteries? J Neurosci Methods 254: 80-85.

48. Asakura K, Matsuo Y, Kanemasa T, Ninomiya M (1997) P/Q-type Ca2+ channe blocker omega-agatoxin IVA protects against brain injury after focal ischemia in rats. Brain Res. 776:140-145.

49. Catterall WA, Few AP (2008) Calcium channel regulation and presynaptic plasticity. Neuron 59: 882-901.

50. Zhen Y, Ding C, Sun J, Wang Y, Li S, et al. (2016) Activation of the calciumsensing receptor promotes apoptosis by modulating the JNK/p38 MAPK pathway in focal cerebral ischemia-reperfusion in mice. Am J Trans I Res 8: 911-921. 